УДК 631.41: 550.42

\title{
СОДЕРЖАНИЕ ХИМИЧЕСКИХ ЭЛЕМЕНТОВ В ПОЧВАХ И ПОВЕРХНОСТНЫХ ВОДАХ ПЛОСКОГОРЬЯ УКОК (ЮГО-ВОСТОЧНЫЙ АЛТАЙ)
}

\author{
Пузанов Александр Васильевич1, \\ puzanov@iwep.ru \\ Бабошкина Светлана Вадимовна ${ }^{1}$, \\ arsenide@rambler.ru
}

Балыкин Сергей Николаевич ${ }^{1}$, snbalykin@yandex.ru

\author{
Рождественская Тамара Анатольевна', \\ rtamara@iwep.ru
}

\author{
Салтыков Алексей Владимирович', \\ saltykovav@yandex.ru \\ 1 Институт водных и экологических проблем СО РАН, \\ Россия, 656038, г. Барнаул, ул. Молодежная, 1.
}

\begin{abstract}
Актуальность исследования обусловлена слабой изученностью химического состава почв и поверхностных вод плоскогорья Укок, являющегося объектом всемирного наследия ЮНЕСКО.

Цель: изучить уровни содержания химических элементов в почвах и поверхностных водах центральной, южной и юго-восточной части плоскогорья Укок и дать эколого-биогеохимическую оценку этой малоизученной территории.

Объекты: основные типы почв (криоаридные и горные лугово-степные, горные луговые, горные тундровые) и поверхностные воды (реки Жумалы, Калгуты, Аргамжи, Ак-Алаха, Тархата и озеро Укок) плоскогорья Укок (Республика Алтай, Российская Федерация).

Методы. Содержание металлов в почвах определено методом эмиссионного спектрального анализа в Институте геологии и минералогии СО РАН, общее содержание микроэлементов в природных водах - в химико-аналитическом иентре ИВЭП СО РАН спектрометрическим методом с использованием электротермической атомизации.

Результаты. Представлен химический состав различных типов почв и поверхностных вод высокогорного плоскогорья Укок. Уровни содержания химических элементов в почвах плоскогорья не превышают их кларков в почвенном покрове и соответствуют их концентрациям в горно-тундровых почвах Алтая. Исключением являются почвы и почвообразующие породы над Калгутинским W-Mo-V-Cu месторождением, где отмечается аномально высокое содержание вольфррама - до 30-60 мг/ка. С ореолами рассеяния и воздействием отвалов штольни и хвостохранилища обогатительной фабрики этого месторождения мы связываем повышенное содержание Си в водах реки Калгуты - 16 мкг/дм³ и в почвах бассейна. Почвы плоскогорья отличаются невысоким валовым содержанием $P$ и Са, но обогащены калием - его содержание превышает 2 \% в большинстве образиов. Концентрация фоссфора в почвах плоскогорья Укок возрастает с запада на восток, от выровненной (центральной) части к горным окаймлениям, что обусловлено фоосфоритоносностью коренных пород Алтае-Саянской горной страны. Низкие значения элювиально-аккумулятивных коэффрициентов большинства металлов в изученных почвах плоскогорья могут служить показателем отсутствия на данный момент здесь выраженного антропогенного загрязнения. Содержание большинства элементов в почвах увеличивается с глубиной. В горно-тундровых торфянистых почвах под ерником обнаружена биогенная аккумуляция $\mathrm{Mn}$. Для степных почв отмечено некоторое накопление в поверхностных горизонтах Zn, Cr, V и Ni. Наиболее равномерным распределением отличается Pb и Zn. Исходная неоднородность моренных и озерноледниковых отложений определяет разнообразие внутрипрофильного распределения металлов в почвах, на них ссрормированных. Не выявлено четкой зависимости содержания большинства макро- и микроэлементов в поверхностных водах от уровня их концентраций в почвах. Тем не менее отмечено повышение интенсивность водной миграции железа в заболоченных ландшасртах Бертекской части бассейна реки Ак-Алаха, в водах которой обнаружено его наиболее высокое содержание.
\end{abstract}

\section{Ключевые слова:}

Юго-Восточный Алтай, плоскогорье Укок, почвы, поверхностные воды, макро- и микроэлементы.

\section{Введение}

Высокогорное плоскогорье Укок расположено на территории Кош-Агачского административного района Республики Алтай. В 1994 г. в южной части плато была создана «Зона покоя Укок», а в 1998 - в составе номинации «Золотые горы Алтая» уникальная территория плоскогорья получила статус объекта Всемирного наследия ЮНЕСКО [1].

Плоскогорье до настоящего времени остается слабо изученным, возможно, вследствие труднодоступности, хотя в последнее время является объектом внимания многих специалистов: климатологов [2], географов [1, 3], ботаников $[4,5]$, почвоведов $[6,7]$. Информация о химическом составе почв и поверхностных вод плоскогорья Укок в литературе практически не встречается. Между тем почвенному покрову уникальных природных ландшафтов горных территорий принадлежит важнейшая роль в поддержании и сохранении биоразнообразия [8-10].

Цель исследования - охарактеризовать содержания химических элементов в почвах и поверхностных водах 
центральной, южной и юго-восточной части плоскогорья Укок и дать эколого-биогеохимическую оценку этой малоизученной территории.

\section{Объекты и методы исследования}

Район исследований расположен в пределах Российской Федерации, Республики Алтай (рис. 1). Территория плато Укок ограничена на юге хребтами Сайлюгем, Табын-Богдо-Ола, Южный Алтай, на севере - ЮжноЧуйским хребтом.

Основными типами почвенного покрова плоскогорья являются: горно-луговые, горно-тундровые, а также горные лугово-степные каштановидные и каштановые почвы [11], названные позднее В.И. Волковинцером [12] степными криоаридными. Биогеохимическая обстановка на исследуемой территории осложняется расположением в северо-восточной ее части Калгутинского W-Mo-V-Cu месторождения. Производственные объекты (штольни, хвостохранилища, установки первичного обогащения руд) находятся на водоразделе рек Калгуты и Жумалы. Эксплуатация предприятия в 2008 г. (после выработки наиболее богатой жилы) была приостановлена. Почвенные профиля (34) заложены в системе ландшафтногеохимических профилей (8) в бассейнах рек: Калгуты, Жумалы, Ак-Алаха, Тархата, Аргамжи и озера Укок (рис. 2). Описание почв и их опробование выполнены по генетическим горизонтам.

Содержание металлов в почвах определяли в Институте геологии и минералогии СО РАН методом эмиссионного спектрального анализа. Проанализировано 143 почвенных образца. Общее содержание микроэлементов в природных водах определено в Институте водных и экологических проблем CO PAH на приборе SOLAAR M6 спектрометрическим методом с использованием электротермической атомизации.

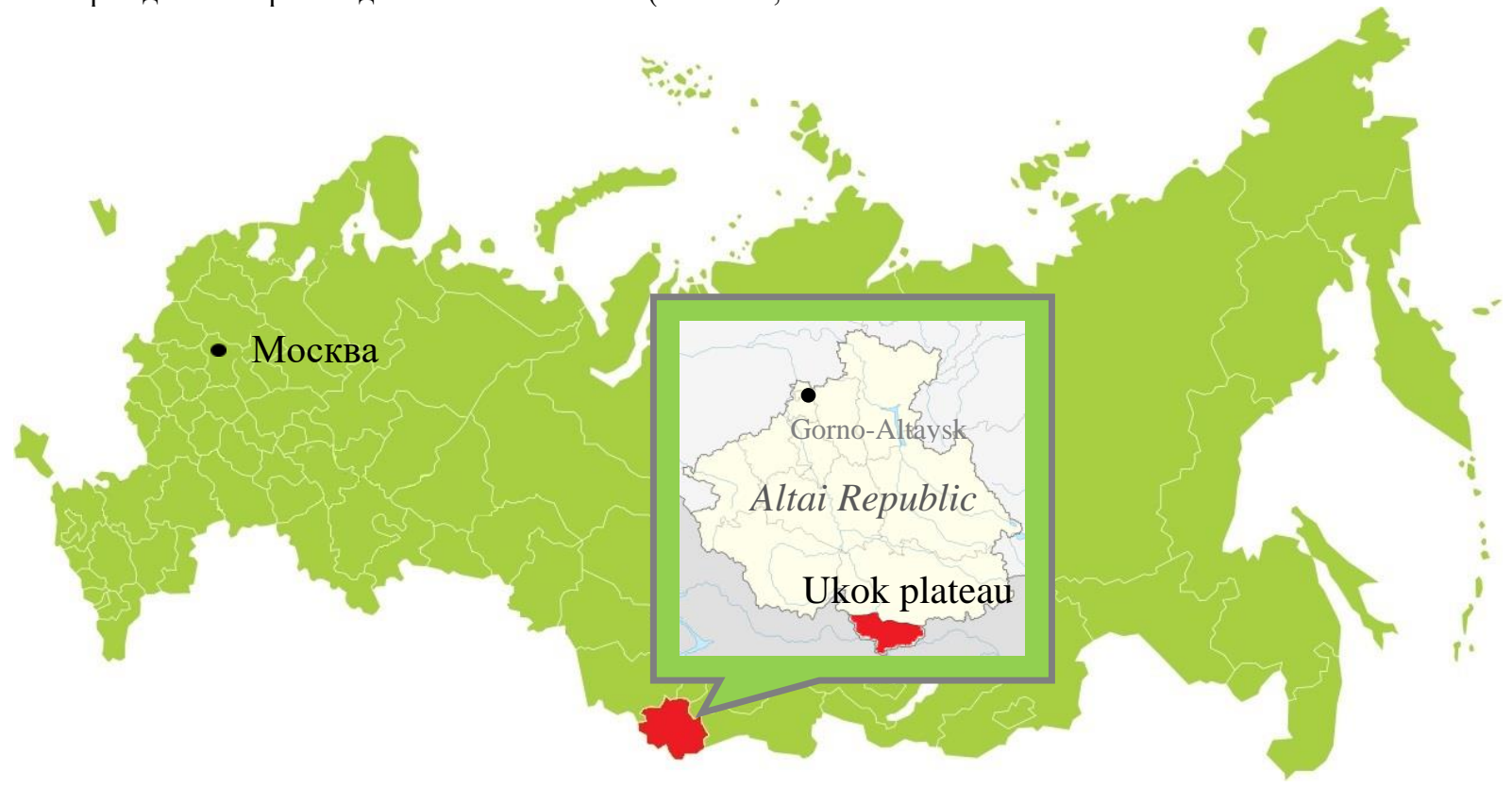

Puc. 1. Расположение района исследований на территории Российской Федерации

Fig. 1. Research area location on the territory of the Russian Federation

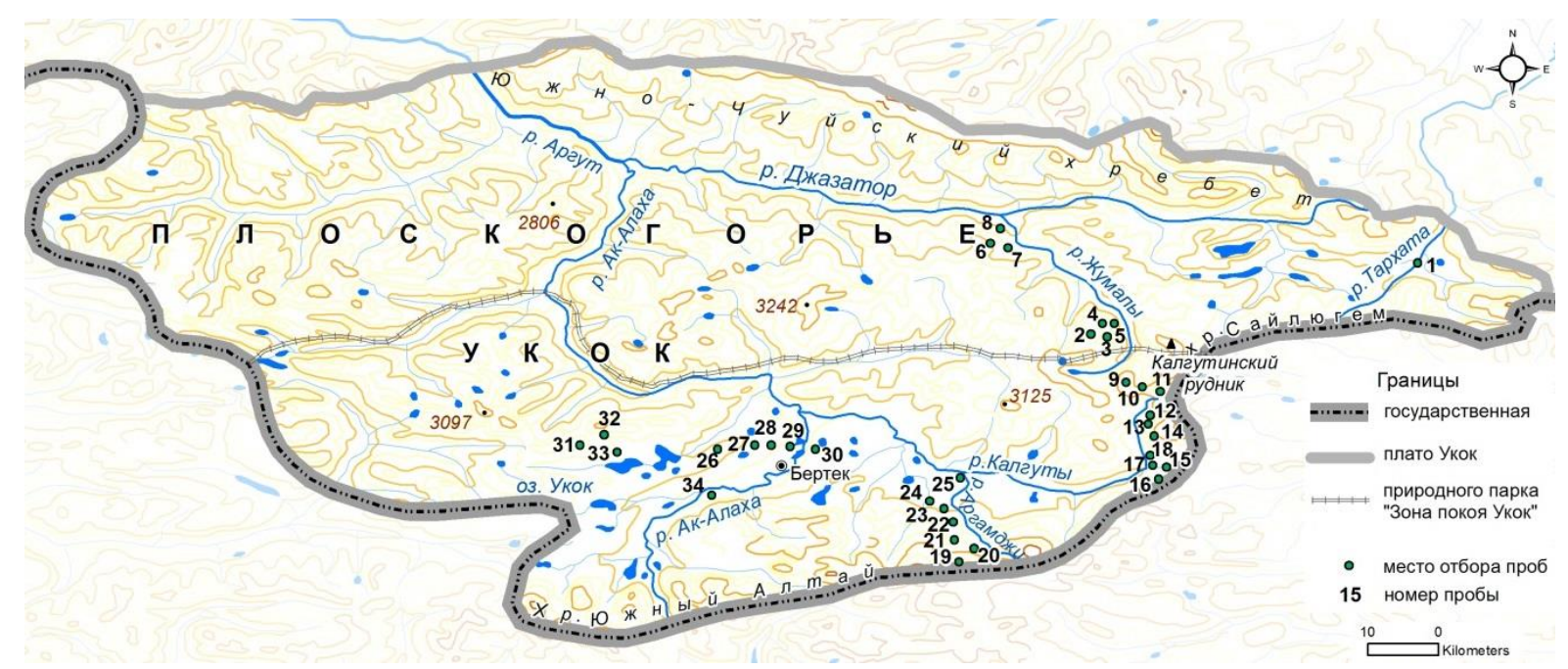

Pис. 2. Расположение почвенных разрезов на плоскогорье Укок

Fig. 2. Soil sections location in the Ukok plateau 
Таблица 1. Концентрации химических элементов (мг/кг) в почвах плоскогорья Укок

Table 1. Chemical elements $(\mathrm{mg} / \mathrm{kg})$ in soils of the Ukok plateau

\begin{tabular}{|c|c|c|c|c|c|}
\hline $\begin{array}{c}\text { Элемент } \\
\text { Chemical element }\end{array}$ & Lim & $\mathrm{M} \pm \mathrm{m}$ & $\mathrm{V}, \%$ & $\begin{array}{c}\text { Кларк в почвах мира [13] } \\
\text { Clark in the soils of the world }\end{array}$ & $\begin{array}{c}\text { Среднее содержание в почвах Западной } \\
\text { Сибири [14] } \\
\text { Average content in soils of Western Siberia }\end{array}$ \\
\hline $\mathrm{Si}$ & $10000-350000$ & $220000 \pm 10000$ & 43 & 330000 & - \\
\hline $\mathrm{Al}$ & $2000-80000$ & $35000 \pm 2000$ & 54 & 71300 & - \\
\hline $\mathrm{Fe}$ & $3000-80000$ & $28000 \pm 1000$ & 62 & 38000 & - \\
\hline $\mathrm{Na}$ & $1000-30000$ & $11000 \pm 50$ & 56 & 63000 & - \\
\hline $\mathrm{K}$ & $6000-230000$ & $20000 \pm 2000$ & 98 & 13600 & - \\
\hline $\mathrm{Ca}$ & $1000-50000$ & $8000 \pm 800$ & 118 & 13700 & $3352 \pm 73$ \\
\hline $\mathrm{Mg}$ & $4000-40000$ & $13200 \pm 480$ & 44 & 18700 & $797 \pm 19$ \\
\hline $\mathrm{Ti}$ & $300-5000$ & $2910 \pm 112$ & 47 & 4600 & $679 \pm 17$ \\
\hline $\mathrm{Mn}$ & $60-5000$ & $656 \pm 46$ & 85 & 850 & $42 \pm 11$ \\
\hline $\mathrm{P}$ & $100-1000$ & $640 \pm 18$ & 36 & 800 & $13 \pm 1$ \\
\hline $\mathrm{Ni}$ & $6-150$ & $42 \pm 1,8$ & 53 & 40 & $84 \pm 1$ \\
\hline $\mathrm{Co}$ & $2-30$ & $12,5 \pm 0,6$ & 56 & 8 & $87 \pm 2$ \\
\hline $\mathrm{Cr}$ & $6-200$ & $62 \pm 3$ & 68 & 200 & $31 \pm 1$ \\
\hline $\mathrm{V}$ & $6-150$ & $69 \pm 3$ & 49 & 88 & $18 \pm 1$ \\
\hline $\mathrm{Cu}$ & $6-200$ & $28 \pm 2$ & 96 & 20 & $73 \pm 1$ \\
\hline $\mathrm{Pb}$ & $3-30$ & $12 \pm 0.5$ & 51 & 10 & $4,3 \pm 0,1$ \\
\hline $\mathrm{Zn}$ & $40-80$ & $51 \pm 1$ & 18 & 60 & - \\
\hline $\mathrm{Mo}$ & $2-8$ & $2,3 \pm 0,1$ & 36 & 2 & \\
\hline $\mathrm{W}$ & $<10-60$ & - & - & 1,3 & \\
\hline
\end{tabular}

Здесь и далее: Lim - предель колебаний, $M$ - среднее содержание, $m$ - ошибка среднего, $n$ - число проб, V-коэффиииент вариации, прочерк-нет данных.

Note: Lim - variation limits, $M$ - average content, $m$ - mean error, $n$ - number of samples, $V$ - coefficient of variation, dash - data are not available.

\section{Результаты и обсуждение}

Валовые содержания $\mathrm{Si}, \mathrm{Al}$, Ti и $\mathrm{Fe}$ в почвах центральной, южной и юго-восточной части плоскогорья Укок заметно ниже их кларков для почв мира [13]. Почвы плоскогорья характеризуются невысоким валовым содержанием Р и Са, но обогащены калием - его содержание превышает $2 \%$ в большинстве образцов. В целом содержания макроэлементов в почвах в границах исследуемой части плоскогорья Укок сопоставимы с величинами их средних содержаний в почвах Западной Сибири (табл. 1) [14]. Среднее валовое содержание $\mathrm{Mn}$ в почвах плоскогорья Укок не превышает уровень его концентраций, характерных для горно-тундровых почв Алтая (681 мг/кг) [15]. Торфяные горизонты горно-тундровых почв под ерниками в бассейне р. Жумалы (разрезы 4, 7), а также верхние горизонты горно-луговых альпийских почв под разнотравно-дриадовыми фитоценозами (разрезы 13, 14, бассейн р. Калгуты) отличаются повышенным содержанием марганца (до 1000 и 5000 мг/кг соответственно). Высоким содержанием Mn (до 3000 мг/кг) отличается верхний (окисленный) слой глеевого надмерзлотного горизонта лугово-болотной почвы в Бертекской котловине (разрез 28).

Валовое содержание $\mathrm{Cu}$ в почвах исследуемой территории также существенно варьирует, но в целом соответствует среднему содержанию $\mathrm{Cu}$ в горно-тундровых $(31,9 \pm 3,4$ мг/кг) и горно-луговых $(26,9 \pm 2,9$ мг/кг) почвах Алтая [15]. Повышенным (до 150-200 мг/кг) содержанием $\mathrm{Cu}$ характеризуется горно-тундровая торфянистая почва в бассейне р. Жумалы (разрез 7). Очевидно, на микроэлементный состав компонентов ландшафтов бассейна оказывают влияние не только рудные тела и ореолы рассеяния Калгутинского редкометального месторождения [16], но и объекты горнорудного производства (отвалы штольни, хвостохранилище) [17], расположенные у истоков реки (известно, что медь в процессе извлечения вольфрама и молибдена практически полностью переходила в отходы). Валовой $\mathrm{Zn}$ в почвах исследуемой территории распределяется довольно равномерно. Значения его концентраций согласуются с данными $(52 \pm 1,5$ мг/кг), приведенными для горно-луговых и горно-тундровых почв Алтая [15]. В горной лугово-степной каштановидной почве бассейна р. Тархата отмечено повышенное (превышающее кларк для почв) содержание цинка. Валовое содержание Со в 1/3 всех проб превышает кларк более чем в 2 раза, но в среднем соответствует уровням его концентраций [15], характерных для горнотундровых и горно-луговых почв Алтая $(14,1 \pm 1,0$ и $11,1 \pm 1,3$ мг/кг соответственно). Низким его содержанием отличаются почвы горных склонов в восточной части плоскогорья, повышенным - почвы Бертекской котловины. В почвообразующих породах южных склонов массива Табын-Богдо-Ола (бассейн р. Аргамжи) было обнаружено до 30 мг/кг Со. Среднее содержание V в почвах центральной, южной и юго-западной частей плоскогорья ниже кларка и не превышает его среднюю концентрацию в почвах Алтая. Для верхних горизонтов горно-луговых и горно-тундровых почв в районе озера Укок характерно содержание ванадия меньше 45 мг/кг. Почвы над ореолами рассеяния Калгутинского месторождения отличаются неравномерным характером пространственного распределения ванадия: невысокое его содержание обнаружено в почвах бассейна р. Калгуты, но повышенное (до 150 мг/кг) - в почвах бассейна р. Жумалы, что определяется, возможно, как жильным характером рудопроявления, так и влиянием объектов Калгутинского рудника, расположенных в истоках реки. В исследуемых почвах отмечено значительное варьирование содержания $\mathrm{Cr}$, 
но уровень его концентраций не превышает кларк для почв. В поверхностных горизонтах содержание хрома, как правило, значительно ниже, чем в почвообразующих породах (от 10-60 до 100 мг/кг соответственно), особенно в бассейне р. Жумалы (до 100-150 мг/кг). Среднее валовое содержание $\mathrm{Ni}$ в почвах плоскогорья Укок не превышает значений его концентраций в почвах Алтая 64 мг/кг [18] и находится на уровне кларка. Биогенное накопление Ni в почвах плоскогорья не выражено, что согласуется с выводами других авторов [18]. Максимумы концентраций Ni отмечены в горно-лугово-степной каштановидной почве на аллювиальных отложениях окрестностей оз. Тархатинское (до 150 мг/кг в горизонте В). В почвах и почвообразующих породах над Калгутинским месторождением выявлено наиболее высокое содержание вольфрама (30-60 мг/кг), на порядок превышающее его кларк в почвах [13] - 1,3 мг/кг. Наиболее высокое содержание фосфора характерно для почв западных отрогов хр.
Сайлюгем (разр. 2-8, 12, 13) - до 1500 мг/кг. Заметно меньшим содержанием Р отличаются почвы в бассейне озера Укок - от 100 до 500 мг/кг. Промежуточное положение по содержанию Р (от 500 до 800 мг/кг) занимают почвы Бертекской котловины. Таким образом, уровень содержания фосфора в почвах плоскогорья Укок увеличивается в направлении запад-восток, от выровненной (центральной) части к горным окаймлениям, что объясняется в том числе фосфоритоносностью коренных отложений Алтае-Саянской горной страны [14]. Сравнивая почвы на разных породах, необходимо отметить, что горно-тундровые дерновые почвы травянистых тундр, сформированные на элювиальных и делювиальных отложениях, отличаются заметно меньшим валовым содержанием в мелкоземе $\mathrm{Si}, \mathrm{Al}, \mathrm{Fe}, \mathrm{P}, \mathrm{Mn}, \mathrm{Cu}, \mathrm{Ni}$, чем аналогичные почвы на моренных отложениях (табл. 2), что связано, очевидно, с несколько лучшей переработанностью и отсортированностью материала последних.

Таблица 2. Содержания химических элементов в почвах плоскогорья Укок на различных почвообразующих породах

Table 2. Chemical elements in soils of the Ukok plateau on various soil-forming rocks

\begin{tabular}{|c|c|c|c|c|c|c|c|c|c|c|c|}
\hline \multirow{2}{*}{$\begin{array}{l}\text { Показатель } \\
\text { Statistical indicator }\end{array}$} & $\mathrm{Si}$ & $\mathrm{Ca}$ & $\mathrm{Al}$ & $\mathrm{Fe}$ & $\mathrm{Mn}$ & $\mathrm{P}$ & $\mathrm{Cu}$ & $\mathrm{Pb}$ & $\mathrm{Ni}$ & $\mathrm{Cr}$ & $\mathrm{Co}$ \\
\hline & \multicolumn{4}{|c|}{$\%$} & \multicolumn{7}{|c|}{ Мг/кГ (mg/kg) } \\
\hline \multicolumn{12}{|c|}{$\begin{array}{l}\text { Почвы элювиально-делювиальных отложений, } \mathrm{n}=28 \\
\text { oils of eluvial-deluvial deposits, the number of samples is }\end{array}$} \\
\hline $\mathrm{M} \pm \mathrm{m}$ & $16 \pm 2$ & $0,7 \pm 0,1$ & $3,5 \pm 0,4$ & $3,0 \pm 0,5$ & $515 \pm 35$ & $520 \pm 35$ & $20 \pm 2$ & $8 \pm 1$ & $35 \pm 3$ & $65 \pm 8$ & $12 \pm 1,5$ \\
\hline Lim & $2-35$ & $0,2-4,0$ & $0,2-8,0$ & $0,2-8$ & $60-1000$ & $100-800$ & $6-40$ & $3-20$ & $6-60$ & $10-150$ & $2-30$ \\
\hline $\mathrm{V}, \%$ & 25 & 116 & 66 & 76 & 37 & 38 & 53 & 49 & 54 & 71 & 67 \\
\hline \multicolumn{12}{|c|}{ Почвы на моренных отложениях, $n=23$} \\
\hline $\mathrm{M} \pm \mathrm{m}$ & $24 \pm 2$ & $0,5 \pm 0,1$ & $4,0 \pm 0,5$ & $3,0 \pm 0,5$ & $600 \pm 40$ & $700 \pm 30$ & $30 \pm 3,5$ & $12 \pm 1$ & $50 \pm 4$ & 808 & $15 \pm 1,5$ \\
\hline Lim & $3-30$ & $0,2-1,5$ & $0,5-8,0$ & $0,8-5,0$ & $150-800$ & $602-1000$ & $6-80$ & $6-30$ & $10-80$ & $10-150$ & $2-30$ \\
\hline $\mathrm{V}, \%$ & 33 & 68 & 48 & 49 & 79 & 23 & 58 & 42 & 31 & 47 & 51 \\
\hline \multicolumn{12}{|c|}{$\begin{array}{l}\text { Почвы на морене с выходами коренных пород, } n=39 \\
\text { moraine deposits with bedrock outcrops, the number of sar }\end{array}$} \\
\hline $\mathrm{M} \pm \mathrm{m}$ & $22 \pm 1,5$ & $0,5 \pm 0,1$ & $4,0 \pm 0,3$ & $2,0 \pm 0,2$ & $760 \pm 150$ & $700 \pm 45$ & $30 \pm 5$ & $15 \pm 1$ & $30 \pm 3$ & $43 \pm 6$ & $11 \pm 1$ \\
\hline Lim & $6-35$ & $0,2-1,5$ & $0,4-8,0$ & $0,4-6,0$ & $200-5000$ & $100-1500$ & $8-200$ & $6-30$ & $6-80$ & $6-150$ & $2-30$ \\
\hline $\mathrm{V}, \%$ & 39 & 66 & 50 & 57 & 119 & 39 & 103 & 43 & 53 & 83 & 59 \\
\hline \multicolumn{12}{|c|}{$\begin{array}{c}\text { Почвы на озерно-аллювиальных отложениях котловин, } \mathrm{n}=37 \\
\text { Soils on lacustrine-alluvial sediments of depressions, the number of samples is } 37\end{array}$} \\
\hline $\mathrm{M} \pm \mathrm{m}$ & $25 \pm 1$ & $1,2 \pm 0,2$ & $4,0 \pm 0,2$ & $3,0 \pm 0,3$ & $680 \pm 75$ & $640 \pm 30$ & $20 \pm 2$ & $11 \pm 0,5$ & $50 \pm 4$ & $65 \pm 6$ & $13 \pm 1$ \\
\hline Lim & $6-35$ & $0,2-3,0$ & $0,5-8,0$ & $0,6-5,0$ & $60-3000$ & $300-1000$ & $10-40$ & $6-20$ & $30-150$ & $10-200$ & $2-30$ \\
\hline $\mathrm{V}, \%$ & 27 & 98 & 46 & 50 & 68 & 26 & 46 & 36 & 46 & 60 & 40 \\
\hline
\end{tabular}

Отметим, что сами моренные отложения, как почвообразующая порода, также отличаются заметно более высоким содержанием $\mathrm{Si}, \mathrm{P}$, а также $\mathrm{Cu}, \mathrm{Pb}$, $\mathrm{Ni}$ и $\mathrm{Cr}$, тогда как в хлорит-серицитовых сланцах закономерно отмечается более высокое содержание $\mathrm{Al}, \mathrm{Fe}, \mathrm{Mn}$. Почвы и почвообразующие породы озерно-аллювиальных отложений котловин и речных долин плоскогорья отличаются заметно более высоким валовым содержанием $\mathrm{Si}$ и Са. Вероятно, эти особенности напрямую связаны с происхождением этих отложений, их образованием на месте высохших озер, участием в их составе скелетных частей водных организмов.

В практике геологических, геохимических, палеоклиматических исследований индикационный метод соотношения содержаний различных элементов используется для выяснения условий формирования почв, генезиса, степени зрелости отложений [14, 19]. Так, например, отношение содержания $\mathrm{Sr} / \mathrm{Ba}$ в почвах чувствительно к изменению гидротермических условий и возрастает с усилением аридности климата: в экстрааридных услови- ях величина $\mathrm{Sr} / \mathrm{Ba}$ может превышать 10, в степных районах составляет около 1, а в лесных снижается до 0,1 [13], что объясняется выносом из почвенной толщи более лабильного Sr. В почвах и почвообразующих породах плоскогорья Укок величина $\mathrm{Sr} / \mathrm{Ba}$ редко превышает 1, в среднем составляя $0,59 \pm 0,03$, что свидетельствует о хороших условиях увлажнения и дренажа. Использование соотношения $(\mathrm{K}+\mathrm{Ca}) / \mathrm{Ti}$ основано на том, что Ті является малоподвижным элементом и чем ниже величина отношения $(\mathrm{K}+\mathrm{Ca}) / \mathrm{Ti}$, тем выше степень выветривания материала, слагающего рассматриваемые отложения [19]. В работе по почвам плоскогорья Укок в бассейне р. Акколь авторы отмечают более низкие отношения (в среднем, $6,9 \pm 0,3)$ в почвах на участках, обращенных на север, что свидетельствует, по их мнению, о повышенной степени их зрелости, по сравнению с почвами южных склонов, где отношения $(\mathrm{K}+\mathrm{Ca}) / \mathrm{Ti}$ составляют в среднем $7,1 \pm 0,3$. В исследуемых нами горно-тундровых торфянистых почвах на северных склонах величины соотноше- 
ний $(\mathrm{K}+\mathrm{Ca}) /$ Ті минимальны (в среднем $8,6 \pm 1,9, \mathrm{Cv}=43 \%$ ), что свидетельствует, очевидно, о более интенсивных процессах выветривания, чем в горно-тундровых дерновых почвах более сухих южных склонов, в которых со-

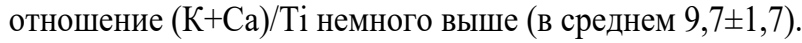

В профильном распределении большинства металлов в почвах изученной территории можно отметить увеличение их концентрации с глубиной, причем более монотонным распределением отличаются почвы с укороченным профилем на элювиальных и делювиальных отложениях (рис. 3, Г).
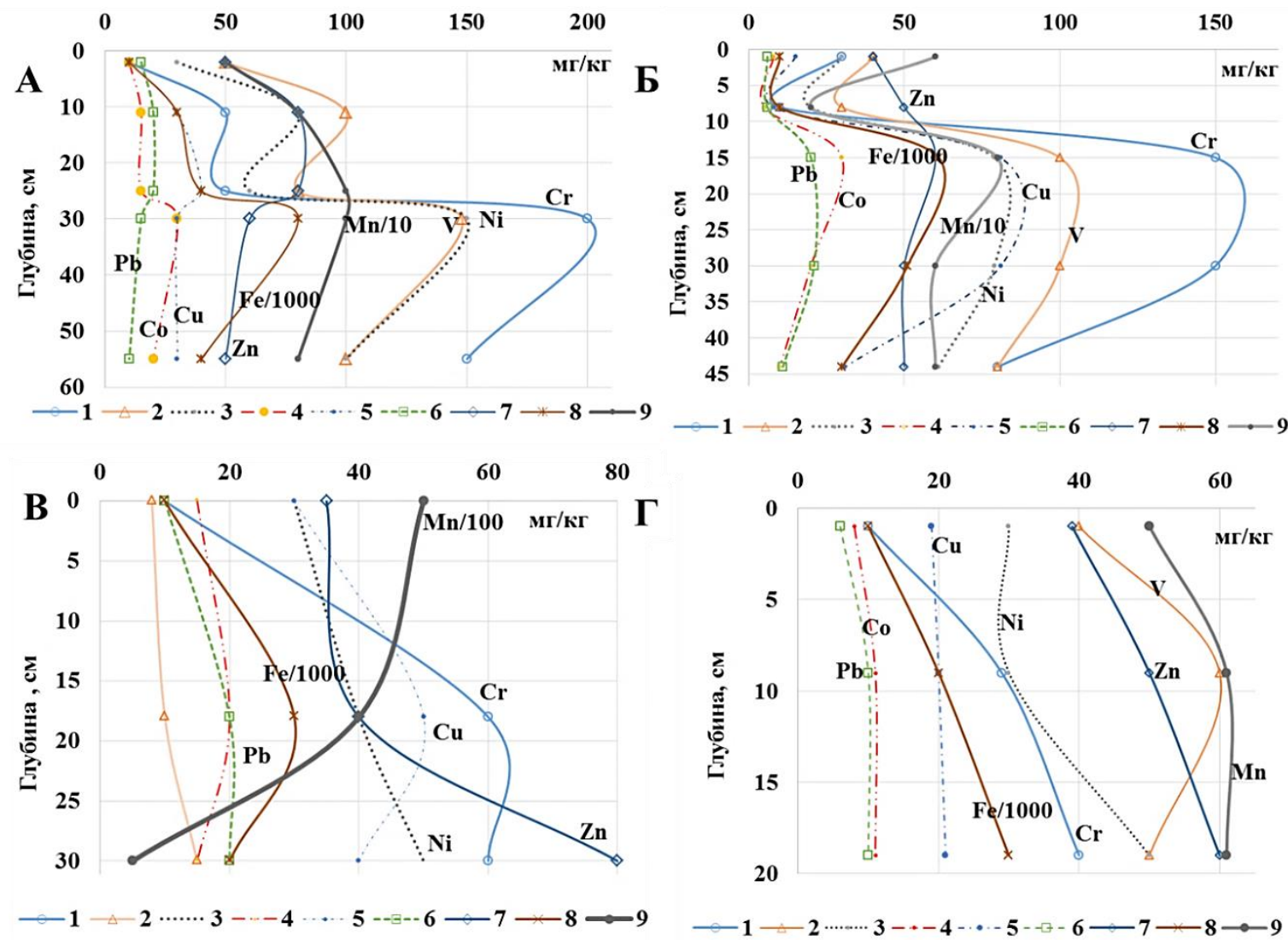

Рис. 3. Радиальное распределение металлов в различных типах почв плоскогорья Укок: А) в каштановых почвах разнотравно-злаковых степей на озерно-аллювиальных отложениях; Б, В) в горно-тундровых торфянистых почвах под ерником (Б) на моренных отложениях с выходами коренных пород, В) на моренных отложениях); Г) в горно-тундровых дерновых почвах под кобрезиевыми растительными сообществами на элювиальных отложениях. $1-\mathrm{Cr}, 2-\mathrm{V}, 3-\mathrm{Ni}$, $4-\mathrm{Co}, 5-\mathrm{Cu}, 6-\mathrm{Pb}, 7-\mathrm{Zn}, 8-\mathrm{Fe} / 1000,9-\mathrm{Mn} / 10(\mathrm{Mn} / 100-$ для B)

Fig. 3. Radial distribution of metals in different soils of the Ukok plateau: A) in chestnut soils (Mollic Leptosols Eutric) of forb-grass steppes on lacustrine-alluvial sediments; $5, B$ ) in mountain tundra peaty soils (Lithic Leptosols Brunic) under yernik (Б) on moraine deposits with bedrock outcrops, B) on moraine deposits); Г) mountain tundra sod soils (Lithic Leptosols Brunic) under kobresia plant communities on eluvial deposits. $1-\mathrm{Cr}, 2-\mathrm{V}, 3-\mathrm{Ni}, 4-\mathrm{Co}, 5-\mathrm{Cu}, 6-\mathrm{Pb}, 7-\mathrm{Zn}, 8-\mathrm{Fe} / 1000,9-$ $\mathrm{Mn} / 10(\mathrm{Mn} / 100-$ for $\mathrm{B})$

Распределение металлов более разнообразно в почвах на моренных и озерно-ледниковых отложениях, что, очевидно, обусловлено их исходной неоднородностью. Небольшое накопление $\mathrm{Zn}, \mathrm{Cr}, \mathrm{V}$, Ni в подгумусовых горизонтах степных почв плоскогорья с выраженным дерновым почвообразовательным процессом (рис. 3, А) связано, возможно, с нисходящим перемещением (просыпанием) гумусированного мелкозема с повышенными концентрациями микроэлементов из верхних горизонтов в нижележащие. Часто и в переходных уплотненных ВС горизонтах можно наблюдать повышенное содержание в мелкоземе $\mathrm{Cr}, \mathrm{V}, \mathrm{Cu}, \mathrm{Ni}$, а также $\mathrm{Fe}$ и $\mathrm{Mn}$ (рис. 3, А, Б). Наиболее равномерным профильным распределением отличается $\mathrm{Pb}$, стоящий в ряду интенсивности поступления микроэлементов в растения на последнем месте [20]. Биогенное накоп- ление в горно-тундровых почвах под ерниковой тундрой характерно для марганца (рис. 3, В). Возможно, это связано с интенсивным его поглощением кустарниками [21]. Низкие значения элювиально-аккумулятивных коэффициентов большинства металлов в изученных почвах плоскогорья могут служить показателем отсутствия здесь явного антропогенного загрязнения.

Общее содержание $\mathrm{Fe}, \mathrm{Mn}, \mathrm{Cu}, \mathrm{Zn}$ в природных поверхностных водах плоскогорья не высокое (табл. 3). Низкое содержание $\mathrm{Si}$ обусловлено преимущественно ледниковым питанием рек плоскогорья. Более высокое содержание $\mathrm{Cu}$ в водах р. Калгуты - 16 мкг/дм ${ }^{3}$, так же, как и в почвах бассейна, очевидно, является проявлением не только ореолов рассеяния Калгутинского месторождения, но связано и с воздействием отвалов штольни и 
хвостохранилища обогатительной фабрики. Четкой зависимости химического состава вод от содержания макрои микроэлементов в почвах нами обнаружено не было. Однако можно отметить, что наиболее высокому содержанию $\mathrm{Mg}$ и $\mathrm{Zn}$ в водах р. Тархата соответствует и повышенное содержание этих элементов в почвах (табл. 3). Обратная зависимость обнаружена для Са. Наименьшее его содержание в почвах бассейна р. Тархата сопровождается его относительно высокими концентрациями в водах реки, что свидетельствует о лабильности Са в условиях окислительной обстановки степных ландшафтов Тархатинской котловины. В отношении железа наблюдается обратная закономерность. При сравнительно высоком его содержании в почвах и почвообразующих породах Тархатинской котловины $(6,0 \pm 3,9$ \%) содержание его в водах р. Тархата (ультрапресных, но в сравнении с другими водотоками, с более высоким содержанием водорастворимых солей -122 мг/ дм ${ }^{3}$ ) самое низкое $\left(0,02\right.$ мг/дм $\left.{ }^{3}\right)$. Степные ландшафты Тархатинской котловины характеризуются невысокой $(K \mathrm{x}=0,27)$ интенсивностью водной миграции железа [22]. Наиболее по- движно железо в заболоченных ландшафтах днища Бертекской котловины. Это обусловлено формированием здесь восстановительной обстановки [23], а также снижением актуальной кислотности почв [24]. При не самом высоком среднем содержании $\mathrm{Fe}$ в почвообразующих породах $(3,0 \pm 0,4$ \%) содержание его в водах р. Ак-Алаха (с низким общим содержанием водорастворимых солей 60 мг/дм $\left.{ }^{3}\right)$ самое высокое из исследуемых природных вод плоскогорья $\left(0,33 \mathrm{мг} /\right.$ дм $\left.^{3}\right)$. Поэтому интенсивность водной миграции $\mathrm{Fe}$ в местами заболоченных ландшафтах Бертекской части бассейна р. Ак-Алаха довольно велика, $\mathrm{Kx}(\mathrm{Fe})=18,3$. Медь наиболее интенсивно поступает в природные воды в пределах водосборного бассейна р. Калгуты $(\mathrm{Kx}=9,1)$, чему способствует рудопроявление Калгутинской W-Mo-Cu зоны, а также воздействие насыщенных медью отходов рудника, расположенных в долине реки. В Бертекской котловине $\mathrm{Kx}(\mathrm{Cu})=8,6$. В бассейне р. Тархата при наиболее высоком содержании $\mathrm{Cu}$ в почвах и почвообразующих породах и невысокой концентрации в природных водах интенсивность её водной миграции наиболее низкая, $\mathrm{Kx}=2,9$.

Таблица 3. Среднее валовое содержание некоторых макро- и микроэлементов в почвах водосборных бассейнов разных рек плоскогорья Укок и их общее содержание в поверхностных водах

Table 3. Average gross content of some macro- and microelements in soils of catchment basins of different rivers of the Ukok plateau and their total content in surface waters

\begin{tabular}{|c|c|c|c|c|c|c|c|}
\hline \multirow{2}{*}{$\begin{array}{c}\text { Показатель } \\
\text { Statistical indicator } \\
\end{array}$} & $\mathrm{Si}$ & $\mathrm{Ca}$ & $\mathrm{Mg}$ & $\mathrm{Mn}$ & $\mathrm{Fe}$ & $\mathrm{Cu}$ & $\mathrm{Zn}$ \\
\hline & \multicolumn{5}{|c|}{$\%$} & \multicolumn{2}{|c|}{ Мг/Кг $(\mathrm{mg} / \mathrm{kg})$} \\
\hline \multicolumn{8}{|c|}{ Почвы бассейна р. Калгуты/Soils of the river Kalguty basin } \\
\hline $\mathrm{M} \pm \mathrm{m}, \mathrm{n}=42$ & $22 \pm 1$ & $0,8 \pm 0,2$ & $1,4 \pm 0,1$ & $550 \pm 30$ & $2,8 \pm 0,3$ & $23 \pm 2$ & $48 \pm 1$ \\
\hline Lim & $8,0-35$ & $0,2-5,0$ & $0,4-3,0$ & $40-1000$ & $1,0-8,0$ & $6-80$ & $40-60$ \\
\hline $\mathrm{V}, \%$ & 40 & 121 & 38 & 37 & 68 & 20 & 17 \\
\hline Кэа, $\mathrm{M} \pm \mathrm{m}, \mathrm{n}=10$ & $0,4 \pm 0,1$ & $0,8 \pm 0,3$ & $0,5 \pm 0,05$ & $0,9 \pm 0,2$ & $0,3 \pm 0,05$ & $0,5 \pm 0,1$ & $0,9 \pm 0,05$ \\
\hline \multicolumn{8}{|c|}{ Поверхностные воды, устье р. Калгуты/Surface water, Kalguty estuary } \\
\hline Содержание, мг/дм $/$ Concentration, $\mathrm{mg} / \mathrm{dm}^{3}$ & 3,0 & 16 & 2,4 & $<0,01$ & 0,11 & 0,016 & 0,005 \\
\hline \multicolumn{8}{|c|}{ Почвы бассейна р. Аргамжи/Soils of the river Argamzhi basin } \\
\hline $\mathrm{M} \pm \mathrm{m}, \mathrm{n}=31$ & $20 \pm 2$ & $1,1 \pm 0,2$ & $1,3 \pm 0,1$ & $520 \pm 30$ & $3,1 \pm 0,3$ & $26 \pm 3$ & $51 \pm 1$ \\
\hline Lim & $6-30$ & $0,1-4,0$ & $0,8-2,0$ & $100-800$ & $0,3-8,0$ & $6-80$ & $40-60$ \\
\hline $\mathrm{V}, \%$ & 48 & 118 & 34 & 33 & 63 & 69 & 13 \\
\hline Кэа, $\mathrm{M} \pm \mathrm{m}, \mathrm{n}=7$ & $0,3 \pm 0,1$ & $0,7 \pm 0,3$ & $0,6 \pm 0,1$ & $0,8 \pm 0,1$ & $0,2 \pm 0,05$ & $0,5 \pm 0,1$ & $1,0 \pm 0,1$ \\
\hline \multicolumn{8}{|c|}{ Поверхностные воды (устье р. Аргамжи)/Surface water (Argamzhi estuary) } \\
\hline Содержание, мг/дм³/Concentration, $\mathrm{mg} / \mathrm{dm}^{3}$ & 0,22 & 12 & 0,4 & $<0,01$ & 0,04 & 0,006 & 0,015 \\
\hline \multicolumn{8}{|c|}{$\begin{array}{l}\text { Почвы бассейна p. Ак-Алаха (Бертекская котловина) } \\
\text { Soils of the river Ak-Alakh basin (Bertek basin) }\end{array}$} \\
\hline $\mathrm{M} \pm \mathrm{m}, \mathrm{n}=27$ & $26 \pm 1$ & $1,0 \pm 0,2$ & $1,2 \pm 0,1$ & $725 \pm 100$ & $2,7 \pm 0,2$ & $21 \pm 2$ & $48 \pm 1$ \\
\hline Lim & $10-30$ & $0,2-4,0$ & $0,6-2,0$ & $60-3000$ & $1,0-5,0$ & $10-40$ & $10-20$ \\
\hline $\mathrm{V}, \%$ & 21 & 87 & 32 & 71 & 36 & 42 & 47 \\
\hline Кэа, $\mathrm{M} \pm \mathrm{m}, \mathrm{n}=$ & $0,9 \pm 0,2$ & $0,3 \pm 0,1$ & $0,7 \pm 0,1$ & $2,7 \pm 1,8$ & $0,7 \pm 0,2$ & $0,8 \pm 0,3$ & $1,1 \pm 0,1$ \\
\hline \multicolumn{8}{|c|}{ Поверхностные воды (устье р. Ак-Алаха)/Surface water (Ak-Alakh estuary) } \\
\hline Содержание, мг/дм $/$ Concentration, $\mathrm{mg} / \mathrm{dm}^{3}$ & 0,77 & 12 & 2,4 & 0,02 & 0,33 & 0,011 & 0,019 \\
\hline \multicolumn{8}{|c|}{ Почвы бассейна оз. Укок/Soils of lake Ukok basin } \\
\hline $\mathrm{M} \pm \mathrm{m}, \mathrm{n}=11$ & $11 \pm 5$ & $0,3 \pm 0,1$ & $1,1 \pm 0,3$ & $570 \pm 160$ & $2,2 \pm 1,2$ & $22 \pm 6$ & $51 \pm 4$ \\
\hline Lim & $1-30$ & $0,1-0,5$ & $0,3-2,0$ & $60-1000$ & $0,3-6,0$ & $6-40$ & $40-60$ \\
\hline $\mathrm{V}, \%$ & 87 & 36 & 45 & 48 & 96 & 48 & 12 \\
\hline Кэа, $\mathrm{M} \pm \mathrm{m}, \mathrm{n}=3$ & $0,2 \pm 0,1$ & $0,6 \pm 0,1$ & $0,4 \pm 0,1$ & $0,6 \pm 0,3$ & $0,2 \pm 0,15$ & $0,5 \pm 0,4$ & $0,8 \pm 0,5$ \\
\hline \multicolumn{8}{|c|}{ Поверхностные (озерные) воды/Surface (lake) waters } \\
\hline Содержание, мг/дм $/$ Concentration, $\mathrm{mg} / \mathrm{dm}^{3}$ & 0,67 & 12 & 2,4 & $<0,01$ & $<0,01$ & 0,003 & 0,005 \\
\hline \multicolumn{8}{|c|}{ Почвы бассейна р. Тархата/Soils of the river Tarkhat basin } \\
\hline $\mathrm{M} \pm \mathrm{m}, \mathrm{n}=7$ & $27 \pm 6$ & $0,4 \pm 0,05$ & $1,8 \pm 0,7$ & $820 \pm 120$ & $4,0 \pm 1,5$ & $28 \pm 7$ & $65 \pm 9$ \\
\hline Lim & $10-35$ & $0,3-0,5$ & $0,6-3,0$ & $500-1000$ & $1,0-8,0$ & $10-40$ & $50-80$ \\
\hline $\mathrm{V}, \%$ & 36 & 22 & 61 & 25 & 64 & 25 & 24 \\
\hline Кэа, $\mathrm{M} \pm \mathrm{m}, \mathrm{n}=1$ & 0,3 & 1,7 & 0,2 & 0,6 & 0,25 & 0,3 & 1 \\
\hline \multicolumn{8}{|c|}{ Поверхностные воды (устье р. Тархата)/Surface waters (Tarkhat estuary) } \\
\hline Содержание, мг/дм ${ }^{3} /$ Concentration, $\mathrm{mg} / \mathrm{dm}^{3}$ & 2,84 & 32 & 7,2 & $<0,01$ & 0,02 & 0,010 & 0,020 \\
\hline
\end{tabular}

Примечания: Кэа - элювиально-аккумулятивный коэффициент.

Note: Кэa-eluvial-accumulative coefficient. 


\section{Выводы}

1. Концентрации большинства химических элементов в почвах центральной, южной и юго-восточной частей плоскогорья Укок не превышают их кларки в почвах и в целом соответствуют уровню их содержания в высокогорных почвах Алтая. Содержание $\mathrm{Si}, \mathrm{Al}, \mathrm{Ti}, \mathrm{Fe}$, Р и Na в почвах изученной территории заметно ниже кларка. Почвы плоскогорья обогащены К.

2. Почвы на элювиальных и делювиальных отложениях плоскогорья Укок отличаются заметно меньшим валовым содержанием в мелкоземе $\mathrm{Si}, \mathrm{Al}, \mathrm{Fe}, \mathrm{P}, \mathrm{Mn}$, $\mathrm{Cu}, \mathrm{Ni}$, чем почвы, сформированные на моренных отложениях. Почвы и почвообразующие породы озерно-аллювиальных отложений котловин и речных долин характеризуются более высоким валовым содержанием Si и Са. В элювиальных почвообразующих породах метаморфического происхождения хлорит-серицитовых сланцах - отмечается более высокое содержание $\mathrm{Al}, \mathrm{Fe}, \mathrm{Mn}$.

\section{СПИСОК ЛИТЕРАТУРЫ}

1. Укок (прошлое, настоящее, будущее) / А.Н. Рудой, 3.В. Лысенкова, В.В. Рудский, М.Ю. Шишин. - Барнаул: Изд-во Алтайского государственного университета, 2000. - $172 \mathrm{c}$.

2. Харламова Н.Ф. Климатические особенности плоскогорья Укок и прилегающих территорий // Известия Алтайского государственного университета. - 2004. - Вып. 3 - С. 71-77.

3. Ландшафтное планирование природного парка «Зона покоя Укок» (Республика Алтай) / В.Г. Бабин, Ю.М. Семёнов, А.В. Шитов, М.Г. Сухова, Н.А. Кочеева, О.В. Журавлёва, А.И. Минаев, А.В. Каранин // География и природные ресурсы. 2011. - № 3. - C. 38-45.

4. Дьяченко С.А. Флора плоскогорья Укок и ее охрана: автореф. дис. ... канд. биол. наук. - Барнаул, 2000. -23 с.

5. Макунина Н.И. О тундростепи в горах Южной Сибири // Экология и география растений и растительных сообществ: материаль IV Международной научной конференции. - Екатеринбург: Гуманитарный университет, 2018. - С. 533-537.

6. Ecological-geographical aspects of soil complex types allocation at the Ukok Plateau using remote sensing studies / S.Y. Kudryashova, L.Y. Ditts, A.V. Chichulin, A.S. Chumbaev, G.F. Miller, A.N. Bezborodova // Contemporary problems of ecology. -2012 . V. 5. - № 5. - P. 516-521.

7. Спирина В.З., Раудина Т.В. Особенности почвообразования и пространственного распространения почв высокогорных склонов Юго-Восточного Алтая // Вестник Томского государственного университета. - 2015. - № 2 (30). - С. 6-19.

8. Spehn E., Körner C. Mountain Biodiversity and global change Mountain Biodiversity and global change. - Schopfheim: Print Media Works, 2005. $-10 \mathrm{p}$.

9. Venevsky S., Venevskaia I. Hierarchical systematic conservation planning at the national level: identifying national biodiversity hotspots using abiotic factors in Russia // Biological Conservation. 2005. - V. 124. - P. 235-251.

10. How soil and elevation shape local plant biodiversity in a Mediterranean hotspot / R. Molina-Venegas, A. Aparicio, S. Lavergne, J. Arroyo // Biodiversity and conservation. -2016. - V. 25. - Iss. 6. P. 1133-1149.

11. Почвы Горно-Алтайской автономной области / под ред. Р.В. Ковалева. - Новосибирск: Наука, 1973. - 352 с.
3. Более высоким содержанием фосфора отличаются почвы северо-восточного горного окаймления плоскогорья в связи с фосфоритоносностью коренных пород Алтае-Саянской горной страны, тогда как в депрессиях концентрации фосфора в почвах невысоки.

4. Концентрации большинства элементов в почвах плоскогорья Укок увеличиваются с глубиной. Для марганца характерно биогенное накопление в поверхностных горизонтах горно-тундровых торфянистых почв, развитых под ерниковыми растительными сообществами.

5. Четкой зависимости химического состава вод от содержания большинства макро- и микроэлементов в почвах не выявлено. Тем не менее отмечено влияние ореолов рассеяния Калгутинского месторождения на биогеохимическую обстановку бассейнов рек Калгуты и Жумалы. Формирование восстановительной обстановки на заболоченных участках Бертекской котловины определяет относительно более высокое содержание железа в водах реки Ак-Алаха.

12. Волковинцер В.И. Степные криоаридные почвы. - Новосибирск: Наука, 1978. - 208 c

13. Виноградов А.П. Геохимия редких и рассеянных химических элементов в почвах. - М.: Изд-во АН СССР, 1957. - 234 с.

14. Сысо А.И. Закономерности распределения химических элементов в почвообразующих породах и почвах Западной Сибири. Новосибирск: Изд-во СО РАН, 2007. - 144 с.

15. Ельчининова О.А. Микроэлементы в наземных экосистемах Алтайской горной области: дис. ... д-ра наук. - Барнаул, 2009. $404 \mathrm{c}$.

16. Timofeev I., Kosheleva N., Kasimov N. Contamination of soils by potentially toxic elements in the impact zone of tungsten-molybdenum ore mine in the Baikal region: a survey and risk assessment // The Science of the Total Environment. - 2018. V. 642. - P. 63-76.

17. Kosheleva N.E., Kasimov N.S., Timofeev I.V. Potentially toxic elements in urban soil catenas of W-Mo (Zakamensk, Russia) and $\mathrm{Cu}$ Mo (Erdenet, Mongolia) mining areas // Journal of soils and sediments. - 2018. - V. 18. - Iss. 6. - P. 2318-2334.

18. Архипов И.А. Никель в почвах Алтая // Мир науки, культуры, образования. - 2008. - № 2 (9). - С. 16-19.

19. Egli M., Lessovaia S.N., Chistyakov K., Inozemzev S., Polekhovsky Yu., Ganyushkin D. Microclimate affects soil chemical and mineralogical properties of cold alpine soils of the Altai Mountains (Russia) // Journal of Soils and Sediments. - 2015. - V. 15. - Iss. 6. - P. 1420-1436

20. Kabata-Pendias A. Trace elements in soils and plants. $4^{\text {rd }}$ ed. - Boca Raton: CRC Press, 2011. - 534 p.

21. Мальгин М.А. Биогеохимия микроэлементов в Горном Алтае. Новосибирск: Наука, 1978. - 272 с

22. Перельман А.И. Геохимия ландшафта. - М.: Изд-во «Высшая школа», 1975. - $342 \mathrm{c}$.

23. Iron speciation at the riverbank surface in wetland and potential impact on the mobility of trace metals / G. Ratie, D. Vantelon, E.L. Kalahroodi, I. Bihannic, A.C. Pierson-Wickmann, M. Davranche // Science of the total environment. - 2019. - V. 651. - P. 1. - P. 443-455.

24. The influence of climate and topography on chemical weathering of granitic regoliths in the monsoon region of China / M. Haireo, Z. Zhiqi, C. Lifeng, L. Congqiang // Acta Geochimica. - 2018. V. 37. - Iss. 5. - P. 758-768. 
Известия Томского политехнического университета. Инжиниринг георесурсов. 2020. Т. 331. № 1. 34-43

Информация об авторах

Пузанов А.B., доктор биологических наук, директор Института водных и экологических проблем СО РАН.

Бабошкина C.B., кандидат биологических наук, старший научный сотрудник Института водных и экологических проблем СО РАН.

Балыкин С.Н., кандидат биологических наук, старший научный сотрудник Института водных и экологических проблем СО РАН.

Рождественская T.A., кандидат биологических наук, старший научный сотрудник Института водных и экологических проблем СО РАН.

Cалтыков A.B., научный сотрудник Института водных и экологических проблем СО РАН, Россия. 
UDC 631.41: 550.42

\title{
CHEMICAL ELEMENTS IN SOILS AND SURFACE WATERS OF THE UKOK PLATEAU (SOUTH-EASTERN ALTAI)
}

\author{
Aleksandr V. Puzanov, \\ puzanov@iwep.ru
}

Svetlana V. Baboshkina, arsenide@rambler.ru

Sergey N. Balykin, snbalykin@yandex.ru

Tamara A. Rozhdestvenskaya, rtamara@iwep.ru

\author{
Aleksey V. Saltykov, \\ saltykovav@yandex.ru \\ 1 Institute for Water and Environmental Problems SB RAS, \\ 1, Molodezhnaya street, Barnaul, 656038, Russia.
}

The relevance of the research is in the poorly studied chemical composition of soils and surface waters of the Ukok plateau - the UNESCO world heritage site.

The aim of the research is to study chemical elements content level in soils and surface waters of the central, southern and south-eastern parts of the Ukok plateau, to give an ecological and biogeochemical assessment of this little-studied area.

Objects: main soil types (Mollic Leptosols Eutric, Umbric Leptosols Dystric, Lithic Leptosols Brunic) and surface water (rivers Zhumaly, Kalguty, Argamzhi, Ak-Alakh, Tarkhat and lake Ukok) of the plateau Ukok (Altai Republic, Russian Federation).

Methods. Metal content in soils was determined by the approximate-quantitative emission spectral analysis at the Institute of Geochemistry and Mineralogy of SB RAS, while the content of trace elements in natural waters was defined by means of the atomic absorption spectrometry using electrothermal atomization at the Chemical Analytical Center of IWEP SB RAS.

Results. The paper presents the results of studying chemical composition of different types of soils and surface waters of the high-mountain plateau Ukok. The concentrations of chemical elements in soils of the plateau do not exceed their Clarks in the soil cover and correspond to those in the mountain-tundra soils of Altai, except for the soils and parent rocks above the Kalguty W-Mo-V-Cu deposit distinguished by the abnormally high content of tungsten (up to 30-60 mg/kg). The increased content of Cu in the waters of the river Kalguty $\left(16 \mu \mathrm{g} / \mathrm{dm}^{3}\right)$ and the soils of the basin is related to the halos and the influence of pilings and tailings of the concentration plant. The plateau soils are characterized by low gross content of $P$ and $\mathrm{Ca}$ needed for plants, but enriched with potassium, the content of which exceeds $2 \%$ in more than half of the samples. In soils of the Ukok plateau, $P$ content increases from west to east, from true surface (central) part to the edging mountains that is due to phosphor presence in indigenous rocks of the Altai-Sayan mountain country. At present, low eluvial-accumulative ratios of metals in the studied soils of the plateau are evidence of the lack of pronounced anthropogenic pollution. The content of most elements in soils increases with depth. In mountain-tundra peat soils, the biogenic accumulation of $\mathrm{Mn}$ was found under dwarf birches. For steppe soils, some accumulation of $\mathrm{Zn}, \mathrm{Cr}, \mathrm{V}$ and Ni was observed in surface horizons. $\mathrm{Pb}$ and $\mathrm{Zn}$ had the most uniform distribution. The initial heterogeneity of moraine and lake-glacial deposits determines the diversity of intra-profile distribution of metals in the formed soils. Clear dependence of most macro-and microelements content in surface waters on their concentrations in soils was not established. Nevertheless, there was an increase in the intensity of water migration of iron in wetlands of the Bertek part of the Ak-Alakh river basin, where its content was the highest.

\section{Key words:}

South-Eastern Altai, Ukok plateau, soils, surface water, macro- and microelements.

\section{REFERENCES}

1. Rudoy A.N., Lysenkova Z.V., Rudskiy V.V., Shishin M.Yu. Ukok (proshloe, nastoyashchee, budushchee) [Plateau Ukok (past, present, future)]. Barnaul, Altai State University Publ., 2000. 172 p.

2. Kharlamova N.F. Climatic features of the Ukok plateau and surrounding areas. Izvestiya of Altai State University, 2004, Iss. 3, pp. 71-77. In Rus.

3. Babin V.G., Semyonov Yu.M., Shitov A.V., Suxova M.G., Kocheeva N.A., Zhuravlyova O.V., Minaev A.I., Karanin A.V Landscape planning of the natural Park «Ukok rest Zone» (Altai Republic). Geography and Natural Resources, 2011, no. 3, pp. 38-45. In Rus.

4. Dyachenko S.A. Flora ploskogorya Ukok i ee okhrana. Avtoreferat Dis. Kand. nauk [Flora of the Ukok plateau and its protection. Cand. Diss. Abstract]. Barnaul, 2000. 23 p.

5. Makunina N.I. O tundrostepi v gorakh Yuzhnoy Sibiri [About tundra in the mountains of southern Siberia]. Ekologiya $i$ geografiya rasteniy i rastitelnykh soobshchestv. Materialy IV Mezhdunarodnoy nauchnoy konferentsii [Ecology and geography of plants and plant complexes. Proc. of the IV International conference]. Ekaterinburg, Humanitarian university Publ., 2018. pp. 533-537.

6. Kudryashova S.Y., Ditts L.Y., Chichulin A.V., Chumbaev A.S., Miller G.F., Bezborodova A.N. Ecological-geographical aspects of soil complex types allocation at the Ukok Plateau using remote sensing studies. Contemporary problems of ecology, 2012, vol. 5, no. 5 , pp. 516-521.

7. Spirina V.Z., Raudina T.V. Features of soil formation and spatial distribution of soils of high-mountain slopes of the South-Eastern Altai. Tomsk State University Journal, 2015, no. 2 (30), pp. 6-19. In Rus.

8. Spehn E., Körner S. Mountain Biodiversity and global change. Schopfheim, Print Media Works, 2005. 10 p.

9. Venevsky S., Venevskaia I. Hierarchical systematic conservation planning at the national level: identifying national biodiversity 
hotspots using abiotic factors in Russia. Biological Conservation, 2005, vol. 124, pp. 235-251.

10. Molina-Venegas R., Aparicio A., Lavergne S., Arroyo J. How soil and elevation shape local plant biodiversity in a Mediterranean hotspot. Biodiversity and conservation, 2016, vol. 25, Iss. 6 , pp. 1133-1149.

11. Pochvy Gorno-Altayskoy avtonomnoy oblasti [Soils of the GornoAltai Autonomous region]. Ed. by R.V. Kovalev. Novosibirsk, Nauka Publ., 1973. $352 \mathrm{p}$.

12. Volkovintser V.I. Stepnye krioaridnye pochvy [Steppe cryoarid soils]. Novosibirsk. Nauka Publ., 1978. 208 p.

13. Vinogradov A.P. Geokhimiya redkikh i rasseyannykh khimicheskikh elementov $v$ pochvakh [Geochemistry of rare and trace elements in soils]. Moscow, AS USSR Publ., 1957. 234 p.

14. Syso A.I. Zakonomernosti raspredeleniya khimicheskikh elementov $v$ pochvoobrazuyushchikh porodakh $i$ pochvakh Zapadnoy Sibiri [Regularities of distribution of chemical elements in soil-forming rocks and soils of Western Siberia]. Novosibirsk, SO RAN Publ., 2007. $144 \mathrm{p}$.

15. Elchininova O.A. Mikroelementy $v$ nazemnykh ekosistemakh Altayskoy gornoy oblasti. Dis. Dokt. nauk [Trace elements in terrestrial ecosystems of the Altai mountain region. Dr. Diss.] Barnaul, 2009. 404 p.

16. Timofeev I., Kosheleva N., Kasimov N. Contamination of soils by potentially toxic elements in the impact zone of tungstenmolybdenum ore mine in the Baikal region: a survey and risk assessment. The Science of the Total Environment, 2018, vol. 642, pp. 63-76.

17. Kosheleva N.E., Kasimov N.S., Timofeev I.V. Potentially toxic elements in urban soil catenas of W-Mo (Zakamensk, Russia) and
Cu-Mo (Erdenet, Mongolia) mining areas. Journal of soils and sediments, 2018, vol. 18, Iss. 6, pp. 2318-2334.

18. Arkhipov I.A. Nickel in the soils of the Altai Republic. The World of Science, Culture, Education, 2008, no. 2 (9), pp. 16-19. In Rus.

19. Egli M., Lessovaia S.N., Chistyakov K., Inozemzev S., Polekhovsky Yu., Ganyushkin D. Microclimate affects soil chemical and mineralogical properties of cold alpine soils of the Altai Mountains (Russia). Journal of Soils and Sediments, 2015, vol. 15, Iss. 6, pp. 1420-1436.

20. Kabata-Pendias A. Trace elements in soils and plants. $4^{\text {rd }}$ ed. Boca Raton, CRC Press, 2011. $534 \mathrm{p}$

21. Malgin M.A. Biogeokhimiya mikroelementov $v$ Gornom Altae [Biogeochemistry of trace elements in the Altai mountains]. Novosibirsk, Nauka Publ., 1978. 272 p.

22. Perelman A.I. Geokhimiya landshafta [Geochemistry of landscape]. Moscow, Vysshaya shkola Publ., 1975. 342 p.

23. Ratie G., Vantelon D., Kalahroodi E.L., Bihannic I., PiersonWickmann A.C., Davranche M. Iron speciation at the riverbank surface in wetland and potential impact on the mobility of trace metals. Science of the total environment, 2019, vol. 651, P. 1, pp. $443-455$.

24. Haireo M., Zhiqi Z., Lifeng C., Congqiang L. The influence of climate and topography on chemical weathering of granitic regoliths in the monsoon region of China. Acta Geochimica, 2018, vol. 37, Iss. 5 , pp. $758-768$.

Received: 25 March 2019

\section{Information about the authors}

Aleksandr V. Puzanov, Dr. Sc., professor, director, Institute for Water and Environmental Problems SB RAS.

Svetlana V. Baboshkina, Cand. Sc., senior researcher, Institute for Water and Environmental Problems SB RAS.

Sergey N. Balykin, Cand. Sc., senior researcher, Institute for Water and Environmental Problems SB RAS.

Tamara A. Rozhdestvenskaya, Cand. Sc., senior researcher, Institute for Water and Environmental Problems SB RAS.

Aleksey V. Saltykov, researcher, Institute for Water and Environmental Problems SB RAS. 